\title{
sciendo
}

CIVIL AND ENVIRONMENTAL ENGINEERING REPORTS

E-ISSN 2450-8594

CEER 2021; 31 (1): 0118-0138

DOI: $10.2478 /$ ceer-2021-0009

Original Research Article

\section{ANALYTICAL MODELS FOR OPTIMAL DESIGN OF A TRAPEZOIDAL COMPOSITE CHANNEL CROSS-SECTION}

\author{
Somayyeh POURBAKHSHIAN ${ }^{1}$, Majid POURAMINIAN ${ }^{2}$ \\ 1,2 Department of Civil Engineering, Ramsar Branch, Islamic Azad University, Ramsar, Iran
}

\begin{abstract}
In this paper, several analytical models are presented for the optimal design of a trapezoidal composite channel cross-section. The objective function is the cost function per unit length of the channel, which includes the excavation and lining costs. To define the system, design variables including channel depth, channel width, side slopes, freeboard, and roughness coefficients were used. The constraints include Manning's equation, flow velocity, Froude number, and water surface width. The Simultaneous Perturbation Stochastic Approximation (SPSA) algorithm was used to solve the optimization problem. The results are presented in three parts; in the first part, the optimal values of the design variables and the objective function are presented in different discharges. In the second part, the relationship between cost and design variables in different discharges is presented in the form of conceptual and analytical models and mathematical functions. Finally, in the third part, the changes in the design variables and cost function are presented as a graph based on the discharge variations. Results indicate that the cost increases with increasing water depth, left side slope, equivalent roughness coefficient, and freeboard.
\end{abstract}

Keywords: trapezoidal composite channel, optimal design, analytical model, SPSA algorithm, freeboard

\footnotetext{
${ }^{1}$ Corresponding Author: Ramsar Branch, Islamic Azad University, Assistant Professor Somayyeh Pourbakhshian, E-mail: s.pourbakhshian@iauramsar.ac.ir
} 


\section{INTRODUCTION}

The optimal design of a channel cross-section reduces the cost along the channel. The optimal geometric dimensions of a channel's cross-section are determined such that the cost of channel construction is minimized and the flow passing through it is maximized [1]. The design of a composite channel cross-section with various sides and bed lining materials is less expensive than a simple cross-section $[2,3]$. Guo and Hughes [1] considered the freeboard as an input parameter to optimize the trapezoidal channel cross-section. Loganathan [4] optimized the parabolic canal by considering the freeboard and limits of velocity and geometric dimensions of the cross-section. An open channel cross-section with the least area or maximum velocity is the most economically efficient because of requiring the least amount of excavation and minimum lining area [5]. In all the above studies, the uniform roughness coefficient was considered along the bed and sides of the channel cross-section. In channels where the roughness coefficients of the bed and sides are different, an equivalent roughness coefficient is considered for uniform flow calculations [2]. Das [3] optimized the cross-section of a trapezoidal composite channel using the Lagrange multiplier method. The objective function consisted of the channel construction cost (excavation and lining costs) per unit of channel length, and constraints included the Manning's equation and positive values of the design variables such as channel depth and width. Horton's equation was applied to calculate the equivalent roughness coefficient. Swamee et al. [6] designed the optimal shape of the open channel cross-section with the objective function of the channel construction cost including excavation and lining costs and water loss. Babaeyan-Koopaei et al., [7] using the Lagrange multiplier method, showed that the Parabolic-bottomed triangle canal cross-section, when compared to trapezoidal and parabolic cross-sections, has a lower cross-sectional area, and a wetted perimeter for the same and specific values of discharge, bed and side slopes, and roughness coefficients. As a result, the excavation and lining costs of this cross-section are lower. Therefore, the parabolic-bottomed Triangle cross-section is more economical than the trapezoidal and parabolic channels. Jain et al. [8] applied Lotter's equation to calculate the equivalent roughness coefficient in Manning's equation. The advantage of Lotter's equation compared to Horton's is that the velocity varies in channel bed and sides that have different roughness coefficients. The Optimization was performed by a genetic algorithm (GA). Chahar [9] presented the optimal parabolic cross-section design equations without considering the freeboard. These equations were used to minimize the excavation and lining costs and were obtained in an explicit shape using the Fibonacci search method. This researcher also used non-dimensional parameters for simplifying the model and presented graphs for these parameters. Bhattacharjya [10] presented the optimal design of a trapezoidal composite 
channel cross-section using the SQP algorithm with respect to the freeboard and safety factor. Since changes in water depth lead to specific energy changes in the channel, this author considered freeboard changes based on specific energy changes and used a safety factor to investigate the impact of other factors on water surface fluctuation. Bhattacharjya [11] designed the optimal stable trapezoidal composite cross-section considering the safety factor as a criterion for the side slope stability. Reddy and Adarsh [12] optimized the cross-section of a trapezoidal composite channel by considering the effect of uncertainty analysis and the probability concept using the GA and PSO heuristic algorithms. Roushangar et al. [13] designed the optimal trapezoidal channel cross-section using the GA algorithm. They investigated the effect of different constraints such as flow depth, top width, Froude number, and the flow velocity separately. Gupta et al. [14] presented the optimal design of a composite trapezoidal cross-section that moves sediment carrier flow in different scenarios using freeboard (constant value and depth-dependent), taking into account minimum cost and maximum hydraulic efficiency. Han et al. [15] used the Lagrange Multiplier optimization method to obtain the most economic section.

Different evolutionary methods, namely the bat algorithm (BA), particle swarm optimization (PSO), and their hybrid (HBP), are employed for the design of trapezoidal open-channel cross-sections studied in [16]. The results indicated that using HBP, compared to BA, PSO, LINGO, the Lagrange multiplier method, and the shuffled frog-leaping algorithm, led to a $32 \%$ saving in construction cost. Therefore, HBP has a high potential for the optimal design of open channels.

Saplioglu et al. [17] proposed an optimal design for a trapezoidal cross-section by changing the discharge and slope angle. At a constant slope angle, with increasing discharge, the cost, bed-width, and height increase. Also, for a constant discharge, the cost and bed-width increase, and the height decreases with increasing slope angle. In this paper, the optimization of a trapezoidal composite channel crosssection is presented more comprehensively as conceptual and analytical models and mathematical functions based on discharge variations. The optimal design of the channel cross-section is determined such that the required discharge passes through it, and the construction cost is minimized.

The difference between the present study and previous works is the optimal design of the trapezoidal composite channel cross-section based on conceptual and analytical models and mathematical equations.

In this regard, considering roughness coefficients as design variables, and a complete set of constraints as well as examining the relationship between design variables and cost function in different discharges, are among the innovations of this study. 


\section{COMPOSITE CHANNEL DESIGN}

\subsection{Channel geometric equations}

When the roughness coefficient is different for each part of the wetted perimeter, an equivalent roughness coefficient is used in Manning's equation [2]. Generally, the construction cost of open channels is lower for a composite channel. Figure 1 shows the cross-section of a trapezoidal composite channel. The geometric parameters of the channel are presented in Table 1.
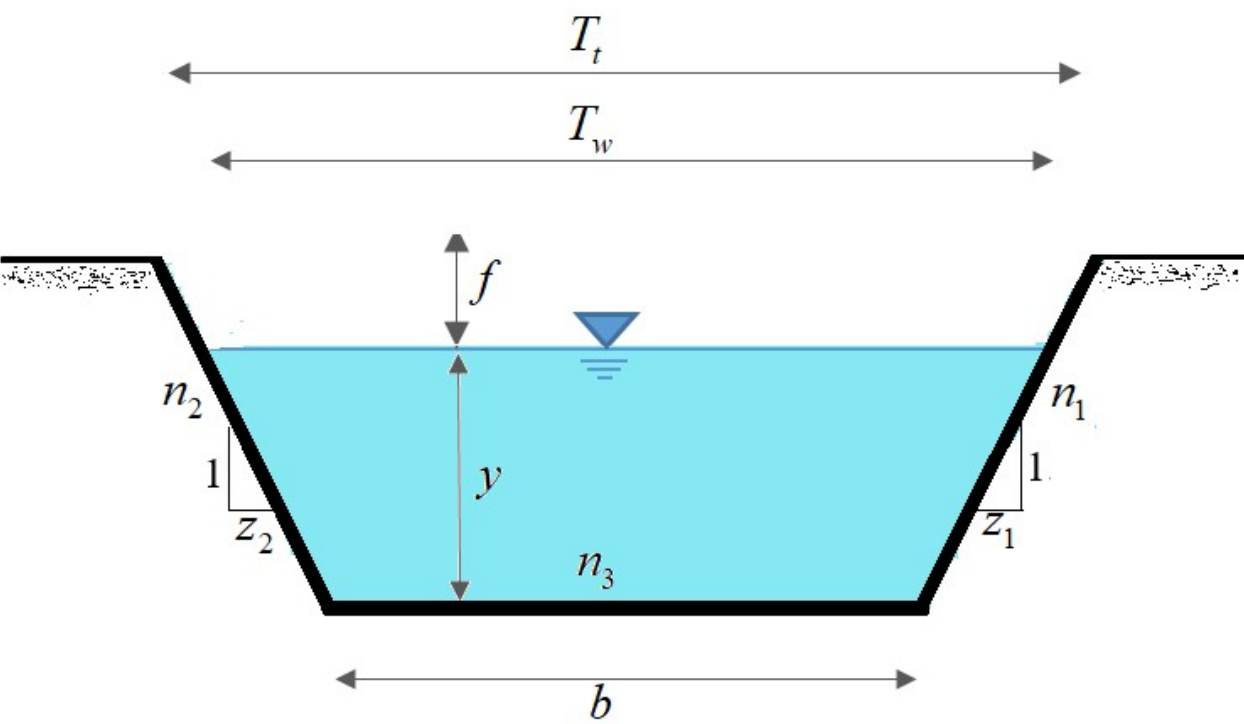

Fig. 1. The geometry of a trapezoidal composite channel cross-section

As shown in Figure 1, $z_{1}: 1, z_{2}: 1$ representing side slopes, $n_{1}, n_{2}, n_{3}$ are Manning's roughness coefficients at the sides and bed of the channel, $b$ is the channel width, y is the flow depth, $\mathrm{f}$ is the freeboard, and $S_{0}$ is the longitudinal bed slope.

$$
\begin{gathered}
A_{t}=b(y+f)+\left(z_{1}+z_{2}\right)(y+f)^{2} / 2 \\
\left.P_{t}=\left\{\left[\left(z_{1}^{2}+1\right)^{(1 / 2)}+\left(z_{2}^{2}+1\right)^{(1 / 2)}\right)\right](y+f)+b\right\}
\end{gathered}
$$




$$
\begin{gathered}
T_{t}=b+\left(z_{1}+z_{2}\right)(y+f) \\
A_{w}=b y+\left(z_{1}+z_{2}\right) y^{2} / 2 \\
\left.\left.P_{w}=\left\{\mid\left(z_{1}^{2}+1\right)^{0.5}+\left(z_{2}^{2}+1\right)^{0.5}\right)\right] y+b\right\} \\
T_{w}=b+\left(z_{1}+z_{2}\right) y \\
P_{w 1}=\left(z_{1}^{2}+1\right)^{(1 / 2)} y \\
P_{w 2}=\left(z_{2}^{2}+1\right)^{(1 / 2)} y \\
P_{w 3}=b \\
P_{t 1}=\left\{\left[\left(z_{1}^{2}+1\right)^{(1 / 2)}\right](y+f)\right\} \\
\left.P_{t 2}=\left\{\left[\left(z_{2}^{2}+1\right)^{(1 / 2)}\right)\right](y+f)\right\} \\
P_{t 3}=b \\
R_{w}=A_{w} / P_{w} \\
A_{w} / T_{w}
\end{gathered}
$$

where $A_{t}$ and $P_{t}$ are the total channel area and perimeter, respectively; $T_{t}$ is the total top width of the channel cross-section; $A_{w \text { and }} P_{w}$ are the channel wetted area and perimeter, respectively; $T_{w}$ is the water surface width, $P_{w 1}, P_{w 2}$, and $P_{w 3}$ are wetted perimeters corresponding to the right and left side slopes and bed of the channel, respectively; $P_{t 1}, P_{t 2}$, and $P_{t 3}$ are perimeters corresponding to the right 
and left side slopes and bed of the channel, respectively; $R_{w}$ is the hydraulic radius; and $D$ is the hydraulic depth. Parameters y, b, z1, z2, and f are defined in Figure 1.

\subsection{Uniform flow design equations for the trapezoidal composite channel}

Eqs. (2.15-2.18) are presented to design a uniform flow for a trapezoidal composite channel. In this study, Horton's equation was applied to calculate the equivalent roughness coefficient [18]. The assumptions of this method are as follows: a) The velocity in each of these component areas is equal to the total flow mean velocity; b) The sum of the component areas is equal to the total flow area; and c) The bed slope of each component is equal to the average channel bed slope.

$$
\begin{gathered}
n e=\left\{\frac{\left.\left[P_{w 1} n_{1}{ }^{1.5}+P_{w 2} n_{2}{ }^{1.5}\right)+P_{w 3} n_{3}{ }^{1.5}\right]}{\left[P_{w 1}+P_{w 2}+P_{w 3}\right]}\right\}^{\frac{2}{3}} \\
Q=\frac{1}{n_{e}} A_{w} R_{w}{ }^{2 / 3} S_{0}{ }^{0.5} \\
F_{r}=\frac{V}{\sqrt{g D}} \\
V=\frac{1}{n_{e}} R_{w}{ }^{2 / 3} S_{0}^{0.5}
\end{gathered}
$$

where $n e$ is the equivalent roughness coefficient based on Horton's equation, $Q$ is the discharge based on Manning's equation for uniform flow, $V$ is the flow velocity, and $F_{r}$ is the Froude number.

\section{THE COMPOSITE CHANNEL OPTIMIZATION METHOD}

In this paper, it is aimed to provide the optimal design for a trapezoidal composite channel cross-section to minimize construction costs under uniform flow conditions, subcritical flow, flow with permissible velocity, and to have permissible water surface width based on design variables, including water depth, channel bed width, Manning's coefficients, cross-section side slopes, and freeboard. 


\subsection{Design variables}

According to the geometric model described in Figure 1, the design variables, their descriptions, and their minimum and maximum values are given in Table 1.

Table 1. Representation of design variables

\begin{tabular}{|c|c|l|c|c|}
\hline$X_{i}$ & unit & \multicolumn{1}{|c|}{ Design variables } & $X_{L}$ & $X_{R}$ \\
\hline$x_{1}=y$ & $\mathrm{~m}$ & Depth of flow & 2 & 15 \\
\hline$x_{2}=b$ & $\mathrm{~m}$ & Channel bed width & 3 & 20 \\
\hline$x_{3}=z_{1}$ & - & Channel right side slope & 0.2 & 2 \\
\hline$x_{4}=z_{2}$ & - & Channel left side slope & 0.2 & 2 \\
\hline$x_{5}=n_{1}$ & - & $\begin{array}{l}\text { Roughness coefficient value corresponding } \\
\text { to the right side of the channel }\end{array}$ & 0.009 & 0.05 \\
\hline$x_{6}=n_{2}$ & - & $\begin{array}{l}\text { Roughness coefficient value } \\
\text { corresponding to the left side of the } \\
\text { channel }\end{array}$ & 0.009 & 0.05 \\
\hline$x_{7}=n_{3}$ & - & $\begin{array}{l}\text { Roughness coefficient value } \\
\text { corresponding to the bed of the channel }\end{array}$ & 0.009 & 0.05 \\
\hline$x_{8}=f$ & $\mathrm{~m}$ & Freeboard & 0.3 & 1.5 \\
\hline
\end{tabular}

\subsection{Constraints}

\subsubsection{Development of uniform flow}

The lining channel is designed to conduct uniform flow [19]. Therefore, in this study, Manning's equation constraint is used to control uniform flow.

$$
\Phi_{1}=\left|\frac{Q n_{e}}{\sqrt{S_{0}}}-\frac{A_{w}^{5 / 3}}{P_{w}^{5 / 3}}\right|-\varepsilon \leq 0 \Rightarrow\left|\frac{Q}{\sqrt{S_{0}}}-\frac{A_{w}^{5 / 3}}{n_{1} P_{w 1}^{1.5}+n_{2} P_{w 2}^{1.5}+n_{3} P_{w 3}^{1.5}}\right|-\varepsilon \leq 0
$$

\subsubsection{Development of subcritical flow}

Also, due to the unstable flow in critical conditions, it is necessary to consider the Froude number constraint in order to avoid the development of critical flow in the optimal design of the channel [10]. In this study, the maximum value of the Froude number is considered to be 0.7 .

$$
\Phi_{2}=\frac{F_{r}}{F_{r_{\max }}}-1 \leq 0
$$




\subsubsection{Water surface width}

In the optimal design of the trapezoidal channel cross-section, the constraint of water surface width is one of the important constraints [3, 8]. Reddy and Adarsh [12] considered the $T_{\max }$ value to be $7 \mathrm{~m}$ for the uniform roughness coefficient and $8 \mathrm{~m}$ for the non-uniform roughness coefficient. The maximum permissible depth is $3.5 \mathrm{~m}$.

\subsubsection{Minimum velocity}

$$
\Phi_{3}=\frac{T_{w}}{T_{\max }}-1 \leq 0
$$

The minimum permissible velocity for preventing sedimentation is in the range 0.6 to $0.9 \mathrm{~m} / \mathrm{s}$, and the minimum velocity for preventing vegetation growth is 0.75 $\mathrm{m} / \mathrm{s}$ [2]. Swamee et al. [17] considered the minimum permissible velocity of the channel design in the range $0.75-0.9$.

\subsubsection{Maximum velocity}

$$
\Phi_{4}=\frac{V_{\min }}{V_{\text {ave }}}-1 \leq 0
$$

In channels with rigid boundaries, the maximum permissible velocity (VL) is the velocity that does not cause erosion. Moreover, to ensure the conveyance of the discharge through the cross-section, the mean actual flow velocity in the channel should not exceed the maximum permissible velocity [8]. In this study, the minimum and maximum velocity values are 0.75 and $4 \mathrm{~m} / \mathrm{s}$, respectively.

\subsection{Objective function}

$$
\Phi_{5}=\frac{V_{\text {ave }}}{V_{\max }}-1 \leq 0
$$

In this study, the objective function is the total construction cost of one metre of a channel, including excavation (cross-sectional area) and surface lining (wetted perimeter) costs. The cost function is as follows:

$$
f_{\cos t}\left(y, b, z_{1}, z_{1}, n_{1}, n_{2}, n_{3}, f\right)=C_{1} A_{t}+C_{2} P_{t 1}+C_{3} P_{t 2}+C_{4} P_{t 3}
$$

where $C_{1}$ is the cost per unit area for cross-sectional area, $C_{2}$ is the cost per unit length for the right side slope of the channel, $C_{3}$ is the cost per unit length for the left side slope of the channel, $C_{4}$ is the cost per unit length for the bed width of the channel, and $A_{t}, P_{t 1}, P_{t 2}$, and $P_{t 3}$ are according to formulas 1, 10, 11, and 12, respectively. The specified values for the four cost elements, i.e., $C_{1}, C_{2}, C_{3}$ and $C_{4}$ , are $0.6,0.2,0.25$, and 0.3 , respectively [3]. 


\section{OPTIMIZATION ALGORITHM}

The SPSA algorithm is a powerful algorithm for optimizing complex systems, developed by Spall in 1998. One of the features of the SPSA algorithm is that in each optimization iteration, irrespective of the number of design variables, it only requires twice the objective function evaluation. Therefore, using this algorithm greatly reduces the computations and the total optimization time [18]. The SPSA is a powerful algorithm in solving civil engineering problems, especially in arch dam optimization [21-23].

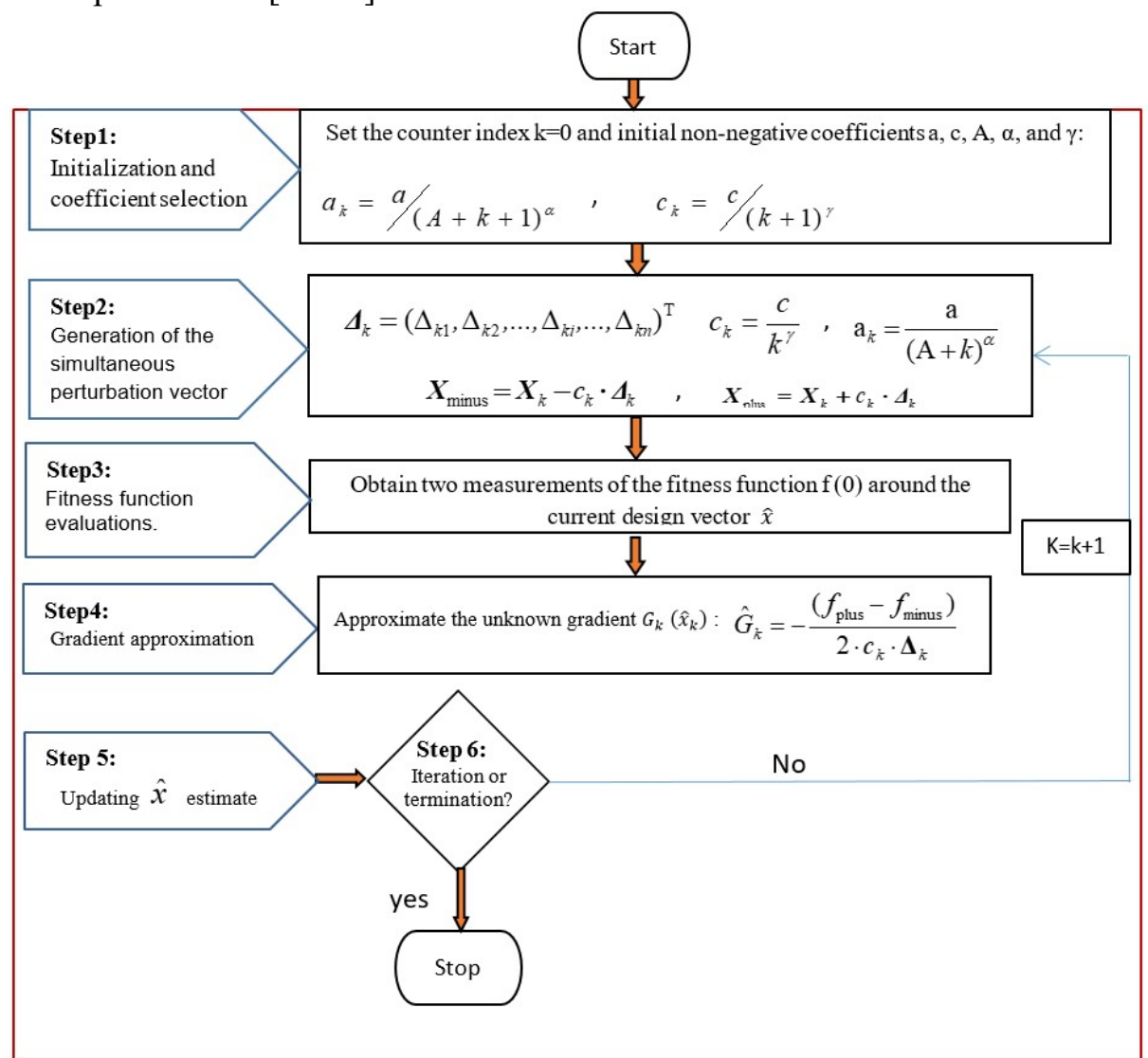

Fig. 2. The flow chart for the SPSA algorithm

The SPSA algorithm is used for optimizing unconstrained problems, therefore, to use it for solving constrained problems with inequality constraints $g_{j} \leq 0(j=1, \ldots, m)$, it is necessary to replace the quasi-objective function $W$ obtained by the external penalty function method with the objective function $f$ : 


$$
w\left(X, r_{p}\right)=f(X)+r_{p} \sum_{j=1}^{m} \max \left[0, g_{j}(X)\right]^{2} \Rightarrow f(\bullet)=w(\bullet)+\text { noise }
$$

$r_{p}$ is a penalty multiplier. The flow chart of the SPSA algorithm for the channel optimization problem can be seen in Figure 2.

\section{OPTIMAL DESIGN STEPS}

Based on the equations presented, the optimal trapezoidal composite channel cross-section is optimized as follows:

1. First, according to Table 1, values are randomly assigned to design variables from the defined range.

2. The constraints of Eqs. (3.1 to 3.5) are calculated for a constant discharge and bed slope.

3. The cost and quasi-cost functions are obtained by Eqs. (3.6) and (4.1). At this step, if the number of permissible optimization iterations is terminated, the program will stop. Otherwise, steps 2 to 5 should be repeated. After the end of the program, the optimal solution is the one that the lowest value of the objective function obtained during the optimization process for which all constraints are also satisfied.

4. For each constant discharge value, 20 successful runs of the optimization algorithm were considered.

5. At each time, the optimal values of each of the design variables, objective function, and constraints are compared with other times, from which a series of conceptual models are obtained. The point is that the top 5 conceptual models are the same for all discharge values.

6. For each specified discharge, three categories of analytical models were determined based on the minimum p-value, the maximum coefficient of determination, the minimum error sum of squares, and the minimum AIC (Akaike Information Criterion). In the first category, the objective function was considered as the dependent variable and the design variables were selected as independent variables. In the second group, design variables and constraints were used as independent variables. In the third category, an analytical model was created between the objective function and each design variable. The first and the second categories are referred to as multivariate regression models and the third category as univariate regression models. 


\section{RESULTS}

In this paper, a series of conceptual and analytical models are presented for the optimal design of a trapezoidal composite channel cross-section. Table 2 compares the Das method [3] with the proposed SPSA Model of the present study. The sum total construction costs in both methods for the Model are 22.954 and 23.731 , respectively.

Table 2. Optimum results for trapezoidal channels design (Das (2000) model and SPSA model)

\begin{tabular}{|c|c|c|}
\hline Parameter & Das(2000) & SPSA model \\
\hline $\mathrm{y}(\mathrm{m})$ & 4.052 & 4.889 \\
\hline $\mathrm{b}(\mathrm{m})$ & 5.826 & 5.550 \\
\hline $\mathrm{Z} 1$ & 0.247 & 0.236 \\
\hline $\mathrm{Z} 2$ & 0.265 & 0.254 \\
\hline $\mathrm{f}(\mathrm{m})$ & 0.5 & 0.306 \\
\hline $\mathrm{Fr}$ & 0.581 & 0.527 \\
\hline $\mathrm{V}$ & 3.596 & 3.269 \\
\hline Cost & 22.954 & 23.731 \\
\hline
\end{tabular}

The optimization process was performed with different discharge values $(50,100$, $200,300,400,500$, and $600 \mathrm{~m} 3 / \mathrm{s}$ ). For each discharge value, 20 runs of the SPSA optimization algorithm were considered, which are referred to as successful projects. The zero-convergence condition of the penalty function was also considered. For each run, the maximum number of iterations was set as 12,000 . In Table 3, a set of conceptual models is presented to show a significant relationship between design variables and construction cost. These conceptual models were obtained by comparing the optimal values of each of the design variables, the objective function, and the constraints at each time with the other times. The most important point in this section is that the top conceptual models that have the highest number of iterations are the same for all the discharge values, indicating the effective correlation between the objective function and the design variables and constraints in these analytical models. The positive and negative signs in these models indicate an increase and decrease in the variables affecting the channel construction cost, respectively. 

CHANNEL CROSS-SECTION

Table 3. Presentation of the best conceptual model based on the dependent variable and independent variables

\begin{tabular}{|c|c|c|}
\hline$Q\left(\frac{m^{3}}{s}\right)$ & \multicolumn{2}{|c|}{ The best conceptual model } \\
\hline 50 & $\frac{y \cdot b \cdot z_{1} \cdot n_{e} \cdot f}{z_{2}} \propto \operatorname{Cos} t$ & $\operatorname{Cost}^{+} \propto y^{+}, b^{+}, z_{1}{ }^{-}, z_{2}{ }^{+}, n_{e}{ }^{+}, f^{+}$ \\
\hline 100 & $\frac{y \cdot z_{2} \cdot n_{e} \cdot f}{b \cdot z_{1}} \propto \operatorname{Cos} t$ & $\operatorname{Cost}^{+} \propto y^{+}, b^{-}, z_{1}{ }^{-}, z_{2}{ }^{+}, n_{e}{ }^{+}, f^{+}$ \\
\hline 200 & $\frac{y \cdot z_{1} \cdot z_{2} \cdot n_{e} \cdot f}{b} \propto \operatorname{Cos} t$ & $\operatorname{Cost}^{+} \propto y^{+}, b^{-}, z_{1}{ }^{+}, z_{2}{ }^{+}, n_{e}{ }^{+}, f^{+}$ \\
\hline 300 & $\frac{y \cdot z_{2} \cdot n_{e} \cdot f}{b \cdot z_{1}} \propto \operatorname{Cost}$ & $\operatorname{Cost}^{+} \propto y^{+}, b^{-}, z_{1}{ }^{-}, z_{2}{ }^{+}, n_{e}{ }^{+}, f^{+}$ \\
\hline 400 & $\frac{y \cdot z_{1} \cdot n_{e} \cdot f}{b \cdot z_{2}} \propto \operatorname{Cos} t$ & $\operatorname{Cost}^{+} \propto y^{+}, b^{-}, z_{1}{ }^{+}, z_{2}{ }^{-}, n_{e}{ }^{+}, f^{+}$ \\
\hline 500 & $\frac{b \cdot z_{2} \cdot n_{e}}{y \cdot z_{1} \cdot f} \propto \operatorname{Cost}$ & $\operatorname{Cost}^{+} \propto y^{-}, b^{+}, z_{1}{ }^{-}, z_{2}{ }^{+}, n_{e}{ }^{+}, f^{-}$ \\
\hline 600 & $\frac{b \cdot z_{2} \cdot n_{e} \cdot f}{y \cdot z_{1}} \propto \operatorname{Cost}$ & $\operatorname{Cost}^{+} \propto y^{-}, b^{+}, z_{1}{ }^{-}, z_{2}{ }^{+}, n_{e}{ }^{+}, f^{+}$ \\
\hline
\end{tabular}

Table 4 shows three top conceptual models for each discharge with the frequency of their iterations. As can be seen, some models are identical at different discharge values.

Among the conceptual models shown in Table 4, the conceptual model $\frac{y \cdot z_{2} \cdot n_{e} \cdot f}{b . z_{1}} \propto$ Cost is more frequent compared to the other models at different discharge values. Therefore, the above conceptual model was used to show the changes in the channel construction cost with design variables and constraints as mathematical models. According to the above equation, the cost increases with increasing water depth, left side slope, equivalent roughness coefficient, and freeboard. In contrast, a significant reduction in the channel bed width and right side slope reduces the channel construction cost. 
Table 4. Presentation of the top three conceptual models based on the dependent variable of cost and independent variables

\begin{tabular}{|c|c|c|c|c|}
\hline \multicolumn{2}{|c|}{$Q\left(\frac{m^{3}}{s}\right)$} & \multicolumn{3}{|c|}{$\begin{array}{l}\text { The top three models with their frequencies in } 20 \text { runs of the } \\
\text { optimization algorithm with } 12,000 \text { iterations for each discharge }\end{array}$} \\
\hline \multirow[b]{2}{*}{$Q_{50}$} & $\begin{array}{l}\text { Number } \\
\text { of Eq }\end{array}$ & 25 & 28 & 41 \\
\hline & Eq. & $\frac{y \cdot z_{2} \cdot n_{e} \cdot f}{b \cdot z_{1}} \propto \operatorname{Cos} t$ & $\frac{y \cdot z_{1} \cdot n_{e} \cdot f}{b \cdot z_{2}} \propto \operatorname{Cos} t$ & $\frac{y \cdot b \cdot z_{2} \cdot n_{e} \cdot f}{z_{1}} \propto \operatorname{Cos} t$ \\
\hline \multirow[b]{2}{*}{$Q_{100}$} & $\begin{array}{l}\text { Number } \\
\text { of Eq }\end{array}$ & 32 & 42 & 51 \\
\hline & Eq. & $\frac{y \cdot b \cdot z_{1} \cdot n_{e} \cdot f}{z_{2}} \propto \operatorname{Cos} t$ & $\frac{y \cdot z_{1} \cdot z_{2} \cdot n_{e} \cdot f}{b} \propto \operatorname{Cos} t$ & $\frac{y \cdot z_{2} \cdot n_{e} \cdot f}{b \cdot z_{1}} \propto \operatorname{Cost}$ \\
\hline \multirow[b]{2}{*}{$Q_{200}$} & $\begin{array}{l}\text { Number } \\
\text { of Eq }\end{array}$ & 24 & 33 & 44 \\
\hline & Eq. & $\frac{y \cdot b \cdot z_{1} \cdot n_{e} \cdot f}{z_{2}} \propto \operatorname{Cost}$ & $\frac{y \cdot z_{2} \cdot n_{e} \cdot f}{b \cdot z_{1}} \propto \operatorname{Cost}$ & $\frac{y \cdot z_{1} \cdot z_{2} \cdot n_{e} \cdot f}{b} \propto \operatorname{Cos} t$ \\
\hline \multirow[b]{2}{*}{$Q_{300}$} & $\begin{array}{l}\text { Number } \\
\text { of Eq }\end{array}$ & 30 & 35 & 36 \\
\hline & Eq. & $\frac{y \cdot b \cdot z_{1} \cdot n_{e} \cdot f}{z_{2}} \propto \operatorname{Cos} t$ & $\frac{y \cdot z_{1} \cdot n_{e} \cdot f}{b \cdot z_{2}} \propto \operatorname{Cos} t$ & $\frac{y \cdot z_{2} \cdot n_{e} \cdot f}{b \cdot z_{1}} \propto \operatorname{Cost}$ \\
\hline \multirow[b]{2}{*}{$Q_{400}$} & $\begin{array}{l}\text { Number } \\
\text { of Eq. }\end{array}$ & 29 & 33 & 36 \\
\hline & $\mathrm{Eq}$ & $\frac{y \cdot z_{1} \cdot n_{e}}{b \cdot z_{2} \cdot f} \propto \operatorname{Cos} t$ & $\frac{y \cdot z_{1} \cdot n_{e} \cdot f}{b \cdot z_{2}} \propto \operatorname{Cos} t$ & $\frac{y \cdot z_{1} \cdot n_{e} \cdot f}{b \cdot z_{2}} \propto \operatorname{Cos} t$ \\
\hline \multirow[b]{2}{*}{$Q_{500}$} & $\begin{array}{l}\text { Number } \\
\text { of Eq. }\end{array}$ & 25 & 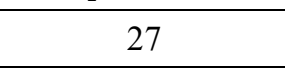 & 48 \\
\hline & $\mathrm{Eq}$ & $\frac{y \cdot b \cdot z_{1} \cdot n_{e} \cdot f}{z_{2}} \propto \operatorname{Cos} t$ & $\frac{y \cdot z_{1} \cdot n_{e} \cdot f}{b \cdot z_{2}} \propto \operatorname{Cos} t$ & $\frac{b \cdot z_{2} \cdot n_{e} \cdot f}{y \cdot z_{1}} \propto \operatorname{Cos} t$ \\
\hline \multirow[b]{2}{*}{$Q_{600}$} & $\begin{array}{l}\text { Numbe } \\
\mathrm{r} \text { of Eq. }\end{array}$ & 24 & 25 & 30 \\
\hline & $\mathrm{Eq}$ & $\frac{b . z_{2} \cdot n_{e}}{y \cdot z_{1} \cdot f} \propto$ Cost & $\frac{y \cdot z_{1} \cdot n_{e}}{b \cdot z_{2} \cdot f} \propto \operatorname{Cos} t$ & $\frac{b \cdot z_{2} \cdot n_{e} \cdot f}{y \cdot z_{1}} \propto \operatorname{Cos} t$ \\
\hline
\end{tabular}

In Table 5, the cost equations are presented based on the design variables for each specified discharge. To evaluate the efficiency of the above equations, the criteria standard error of estimate, coefficient of determination, and $p$-value were used in this study. For each specified discharge value, more than 30 mathematical models were investigated between the channel construction cost and the design variables. Finally, for each specified discharge, a model was selected that has the lowest pvalue, the highest value for the coefficient of determination, and the minimum error sum of squares. 
Table 5. Presentation of cost equations based on design variables for each specified discharge

\begin{tabular}{|c|l|c|c|c|}
\hline $\begin{array}{c}\mathrm{Q} \\
\left(\mathrm{m}^{3} / \mathrm{s}\right)\end{array}$ & $\mathrm{Eq}$ & $\mathrm{SSE}$ & $\mathrm{R}^{2}$ & P-value \\
\hline 50 & $\operatorname{Cos} t=10^{1.4416} \times \frac{10^{\left(y+Z_{1}+Z_{2}\right)}}{10^{(b+n e)} \times f^{0.0092}}$ & 0.0000459 & 100 & 0.0021 \\
\hline 100 & Cost $=10^{0.6337} \times \frac{10^{(y+b+n e)} \times f^{0.230}}{10^{\left(Z_{2}\right)} \times Z_{1}^{0.02149}}$ & 0.0002476 & 100 & 0.0000 \\
\hline 200 & Cost $=10^{0.0121} \cdot \frac{y^{2.1476} \times 10^{b} \times n e^{0.182} \times f^{0.01343}}{Z_{1}^{0.01085} \times 10^{Z_{2}}}$ & 0.0003333 & 100 & 0.00116 \\
\hline 300 & Cost $=10^{9.9338} \cdot \frac{Z_{1}^{0.3924} \times n e^{0.4125} \times f^{0.0226}}{y^{5.0935} \times b^{4.4657} \times Z_{2}{ }^{0.6578}}$ & 0.002355 & 99.89 & 0.0000 \\
\hline 400 & Cost $=10^{3.5473} \times \frac{10^{y} \times Z_{1}^{0.1192} \times n e^{1.1253} \times f^{0.02327}}{10^{b+Z_{2}}}$ & 0.000757 & 100 & 0.0085 \\
\hline 500 & Cost $=10^{3.5473} \times \frac{10^{y+n e} \times f^{0.02646}}{10^{b} \times Z_{1}^{0.06194} \times Z_{2}^{0.00446}}$ & 0.0000191 & 100 & 0.0000 \\
\hline 600 & Cost $=10^{1.2784} \cdot \frac{y^{0.8044} \times Z_{2}^{0.0011} \times n e^{0.03926}}{b^{0.01473} \times Z_{1}^{0.0866} \times f^{0.04932}}$ & 0.0000512 & 100 & 0.01 \\
\hline
\end{tabular}

In Table 6, mathematical models of channel construction cost are presented based on design variables, Froude number, flow velocity, and channel depth for each specified discharge. In this table, the coefficient of determination, standard error of estimate, and AIC were used to evaluate the equations. For each specified discharge value, more than 30 mathematical models were evaluated and, finally, a model was selected with the minimum error sum of squares and the highest value of the coefficient of determination. The p-value shows that with $99 \%$ certainty, all the models are acceptable. $\mathrm{R}^{2}$ and SSE values represent a high correlation between cost and design variables, Froude number, flow velocity, and channel depth for each specified discharge.

In Table 7, for different discharge values, a mathematical model is presented between the channel construction cost and each of the design variables. These models were selected based on the minimum error sum of squares, the maximum value of the coefficient of determination, and the minimum value of the AIC. The Result shows that all the models are acceptable. R, $\mathrm{R}^{2}$, SSE values, and AIC represent a high correlation between cost and each of the design variables. 
Table 6. Presentation of cost equations based on design variables and parameters of Froude number, flow velocity, and channel depth for each specified discharge

\begin{tabular}{|c|c|c|c|c|}
\hline $\begin{array}{c}\mathrm{Q} \\
\left(\mathrm{m}^{3} / \mathrm{s}\right)\end{array}$ & $\mathrm{Eq}$ & SSE & $\mathrm{R}^{2}$ & P-value \\
\hline 50 & Cost $=10^{1.2705} \times \frac{10^{\left(y+Z_{1}+Z_{2}+H\right)}}{10^{(b+n e+F r+V)} \times f^{0.04048}}$ & 0.0000258 & 100 & 0.0083 \\
\hline 100 & Cost $=10^{3.7934} \times \frac{10^{(y+n e)} \times H^{0.1711} \times Z_{2}^{0.00705}}{10^{(F r+V)} \times b^{0.03454} \times Z_{1}^{0.02827} \times f^{0.0502}}$ & 0.0000921 & 100 & 0.049 \\
\hline 200 & Cost $=10^{1.3754} \cdot \frac{10^{y+Z_{1}+f+H} \times b^{0.00091}}{F r^{0.0812} \times V^{0.6838} \times 10^{Z_{2}+n e}}$ & 0.0000393 & 100 & 0.0434 \\
\hline 300 & Cost $=10^{2.5526} \cdot \frac{10^{f+H} \times b^{0.00091}}{n e^{0.00292} \times Z_{2}^{0.00283} \times F r^{0.0522} \times 10^{y+b+Z_{1}+V}}$ & 0.0000447 & 100 & 0.0227 \\
\hline 400 & Cost $=10^{3.6759} \cdot \frac{y^{0.00335} \times 10^{b} \times Z_{2}^{0.00376} \times n e^{1.1139} \times f^{0.0669} \times V^{0.2719}}{Z_{1}^{0.0618} \times F r^{0.02247} \times H^{0.01490}}$ & 0.0000363 & 100 & 0.0013 \\
\hline 500 & Cost $=10^{2.0481} \cdot \frac{10^{y+n e+H} \times f^{0.01694}}{10^{b+F r} \times Z_{1}^{0.00476} \times Z_{2}^{0.0038} \times V^{0.0507}}$ & 0.0000107 & 100 & 0.0000 \\
\hline 600 & Cost $=10^{12.5795} \cdot \frac{y^{1.1004} \times b^{0.01323} \times Z_{2}^{0.0007} \times n e^{0.02413}}{Z_{1}^{0.01772} \times f^{0.01211} \times F r^{0.00137} \times H^{0.05661} \times V^{0.1461}}$ & 0.0000137 & 100 & 0.1000 \\
\hline
\end{tabular}

Table 7. Presentation of the three top conceptual models based on the dependent variable of cost and each independent variable

\begin{tabular}{|c|c|c|c|c|c|}
\hline $\mathrm{Q}\left(\mathrm{m}^{3} / \mathrm{s}\right)$ & & $\mathrm{Eq}$ & SE & $\mathrm{R}^{2}$ & $\mathrm{AIC}$ \\
\hline \multirow{6}{*}{50} & $\mathrm{y}$ & $\left(-1619 \quad .7 / X^{2}\right)-0.032 \quad X+8.23$ & 0.0000 & 1.0000 & -205.161 \\
\hline & $\mathrm{b}$ & $\left(-319.4 / X^{2}\right)-0.11 X+7.25$ & 0.0000 & 1.0000 & -206.570 \\
\hline & $Z_{1}$ & $-3.28 \times 10^{-13} \times\left(2.91 \times 10^{104}\right)^{1 / x} \times X^{5.72}$ & 0.0000 & 1.0000 & -212.007 \\
\hline & $\mathrm{Z}_{2}$ & $-370.15 / X^{2}-0.051 X+0.136$ & 0.0000 & 1.0000 & -219.716 \\
\hline & ne & $0.041+\left(\left(-0.017 X^{-31.84}\right) /\left(22.19^{-31.84}+X^{-31.84}\right)\right)$ & 0.00035 & 0.9992 & -57.583 \\
\hline & $\mathrm{f}$ & $0.14(1+(1.077 \quad X \quad /-41.4))-1 / 1.077$ & 0.0000 & 1.0000 & -211.799 \\
\hline \multirow{6}{*}{100} & $\mathrm{y}$ & $1 /\left(-0.803+0.465 \ln \left(X^{2}\right)-0.0147 \ln \left(X^{3}\right)\right.$ & 0.0219 & 0.9997 & -32.753 \\
\hline & $\mathrm{b}$ & $5.55-2.72 e^{-9.31 \times 10^{10} \times-7.38}$ & 0.1104 & 0.9974 & -0.0755 \\
\hline & $Z_{1}$ & $0.249+\left(\left(111 \quad .83^{-9} X^{-9.154}\right) /\left(15^{.78^{-9.154}}+X^{-9.154}\right)\right)$ & 0.0659 & 0.9764 & -5.231 \\
\hline & $\mathrm{Z}_{2}$ & $0.256+\left(\left(1.393 X^{-16.46}\right) /\left(38.05^{-16.46}+X^{-16.46}\right.\right.$ & 0.0159 & 0.9998 & -19.10 \\
\hline & ne & $0.0164+\left(\left(0.0309 X^{3.989}\right) /\left(40.4166^{3.989}+X^{3.989}\right)\right)$ & 0.00092 & 0.9909 & -89.806 \\
\hline & $\mathrm{f}$ & $5.07 e^{-65.08 / x}$ & 0.16028 & 0.8599 & -28.927 \\
\hline \multirow{3}{*}{200} & $\mathrm{y}$ & $4.218(1+(0.96 \times /-122.51))^{-1 / 0.96}$ & 0.0000 & 1.0000 & -198.74 \\
\hline & $\mathrm{b}$ & $6.578 \quad(1+(-13 \quad .535 \quad x / 961 \quad .3))^{1 / 1.353}$ & 0.0000 & 1.0000 & -192.289 \\
\hline & $Z_{1}$ & $0.270+\left(\left(0.348 X^{-28.313}\right) /\left(55.779-28.313+X^{-28.313}\right.\right.$ & 0.0000 & 1.0000 & -298.984 \\
\hline
\end{tabular}


ANALYTICAL MODELS FOR OPTIMAL DESIGN OF A TRAPEZOIDAL COMPOSITE 133 CHANNEL CROSS-SECTION

\begin{tabular}{|c|c|c|c|c|c|}
\hline & $\mathrm{Z}_{2}$ & $\left(X^{2}\right)+3.639 \quad X-1.719$ & 0.0000 & 1.0000 & -215.375 \\
\hline & ne & $0.0194+\left(\left(0.0245 X^{9.298}\right) /\left(54.3711^{9.298}+X^{9.298}\right)\right)$ & 0.00025 & 0.9995 & -88.023 \\
\hline & f & $0.052+\left(\left(0.348 X^{45.601}\right) /\left(64.9488^{45.601}+X^{45.601}\right)\right)$ & 0.00704 & 0.9994 & -27.595 \\
\hline \multirow{6}{*}{300} & $\mathrm{y}$ & $23.968 \quad-17.319 \quad e^{-1.364 \times 10^{-14} x^{6.026}}$ & 0.0000 & 0.9571 & -1.449 \\
\hline & $\mathrm{b}$ & $9.491 /\left(1+(X / 86.765)^{6.483}\right)$ & 0.0000 & 1.0000 & -201.742 \\
\hline & $\mathrm{Z}_{1}$ & 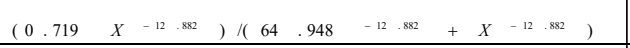 & 0.0000 & 1.0000 & -217.637 \\
\hline & $\mathrm{Z}_{2}$ & $0.202+\left(\left(0.929 X^{128} \cdot 16\right) /\left(82.7911^{128} .16+X^{128} \cdot 16\right)\right)$ & 0.0000 & 1.0000 & -298.984 \\
\hline & ne & $0.0411+\left(\left(-0.0176 \quad X^{-29.52}\right) /\left(78.119-29.52+X^{-29.52}\right.\right.$ & 0.00151 & 0.9820 & -66.517 \\
\hline & f & $0.306+\left(\left(0^{0.665} X^{154.52}\right) /\left(78.065^{154.52}+X^{154.52}\right)\right)$ & 0.0000 & 0.9914 & -23.983 \\
\hline \multirow{6}{*}{400} & $\mathrm{y}$ & $(6.89-0.0593 \quad X) /\left(1-0.011 \quad X+0.000021 \quad X^{2}\right)$ & 0.0000 & 1.0000 & -228.789 \\
\hline & $\mathrm{b}$ & $3.672+\left(\left(5.264 X^{-111.09}\right) /\left(5.264-111.09+X^{-111.09}\right)\right)$ & 0.0000 & 1.0000 & -266.247 \\
\hline & $Z_{1}$ & $1.428(1+(-2.399 \quad X / 298 \quad .09))^{1 / 2.399}$ & 0.00135 & 0.9968 & -37.566 \\
\hline & $\mathrm{Z}_{2}$ & $3.672+\left(\left(5.264 X^{-111.09}\right) /\left(5.264-111.09+X^{-111.09}\right)\right)$ & 0.1105 & 0.9792 & -0.0735 \\
\hline & ne & 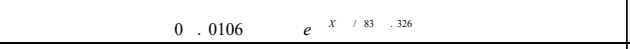 & 0.00157 & 0.9546 & -63.788 \\
\hline & f & $0.3529+\left(\left(0.6501 X^{14.85}\right) /\left(86.311^{14.85}+X^{14.85}\right)\right)$ & 0.0000 & 1.0000 & -283.417 \\
\hline \multirow{6}{*}{500} & $\mathrm{y}$ & $11.212+2.533 \cos (0.0666 X-2.978)$ & 0.0000 & 1.0000 & -271.258 \\
\hline & $\mathrm{b}$ & $-0.000132 X^{3}+0.0495 X^{2}-6.285 X+275.16$ & 0.0000 & 1.0000 & -228.248 \\
\hline & $\mathrm{Z}_{1}$ & $\left(0.957 \quad X^{-6.524}\right) /\left(123 \quad .5999^{-6.524}+X^{-6.524}\right)$ & 0.0000 & 1.0000 & -214.741 \\
\hline & $\mathrm{Z}_{2}$ & $-0.00026 \quad X^{2}+0.0868 \quad X-5.729$ & 0.1636 & 0.8841 & -17.882 \\
\hline & ne & $0.0401+\left(\left(-0.01242 \quad X^{-27.738}\right) /\left(108.151^{-27.738}+X^{-27.738}\right)\right)$ & 0.00125 & 0.9860 & -44.849 \\
\hline & f & $0.000027 \quad X^{3}-0.0085 \quad X^{2} 0.898 \quad X-31.118$ & 0.0000 & 1.0000 & -247.123 \\
\hline \multirow{6}{*}{600} & $\mathrm{y}$ & $0.00051 X^{2}-0.0591 X+10.292$ & 0.0000 & 1.0000 & -171.547 \\
\hline & $\mathrm{b}$ & $\left.12.151 /\left(1+e^{-1133} \quad .68+9.775 \quad x\right)^{(1 / 1384} \quad .691\right)$ & 0.0000 & 0.9753 & -13.142 \\
\hline & $\mathrm{Z}_{1}$ & $\left(379.06 X^{-5.271}\right) /\left(32.130^{-5.271}+X^{-5.271}\right)$ & 0.0000 & 0.5344 & -7.858 \\
\hline & $\mathrm{Z}_{2}$ & $\left(0.972 \quad X^{58.890}\right) /\left(111 \quad .5988^{58.890}+X^{58.890}\right)$ & 0.0000 & 1.0000 & -211.786 \\
\hline & ne & $1.03 \times 10^{-7} X^{4}-4.8913 \times 10^{-5} X^{3}+0.00867 X^{2}-0.681 X+20.031$ & 0.0000 & 1.0000 & -298.074 \\
\hline & $\mathrm{f}$ & $0.335 \quad /(1+3.836 \quad X /-533 \quad .094 \quad)^{(-1 / 3.836)}$ & 0.0000 & 1.0000 & -203.806 \\
\hline
\end{tabular}

Figure 3 presents the correlation between the cost function and the values of the design variables at different discharge values. In fact, these graphs represent the mathematical models of Table 7. The channel construction cost increases with increasing water depth, channel left side slope, equivalent roughness coefficient, and freeboard on the one hand, and with decreasing channel width and channel cross-section right side slope on the other hand. This process is the same in different discharge values. 

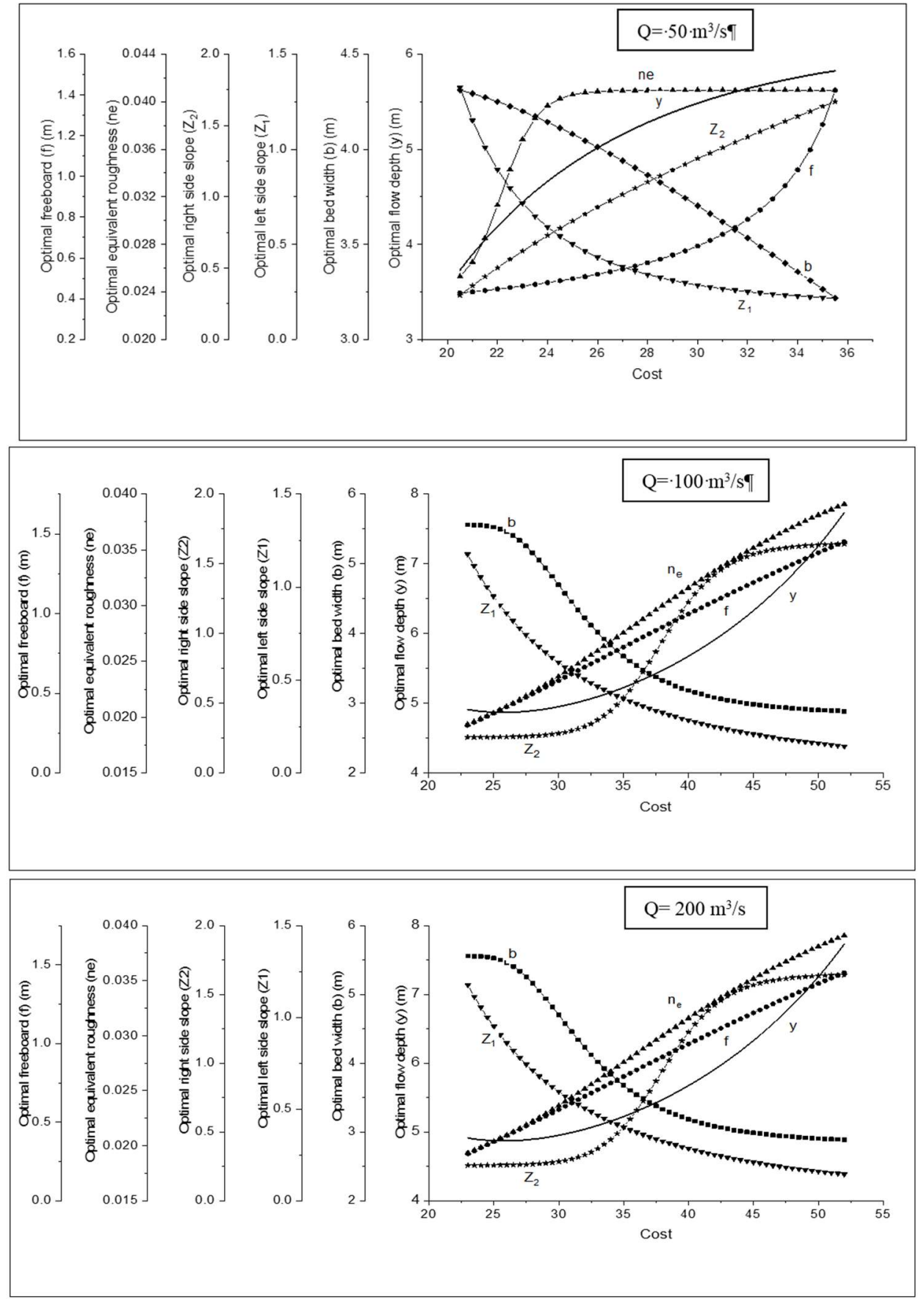
ANALYTICAL MODELS FOR OPTIMAL DESIGN OF A TRAPEZOIDAL COMPOSITE 135 CHANNEL CROSS-SECTION

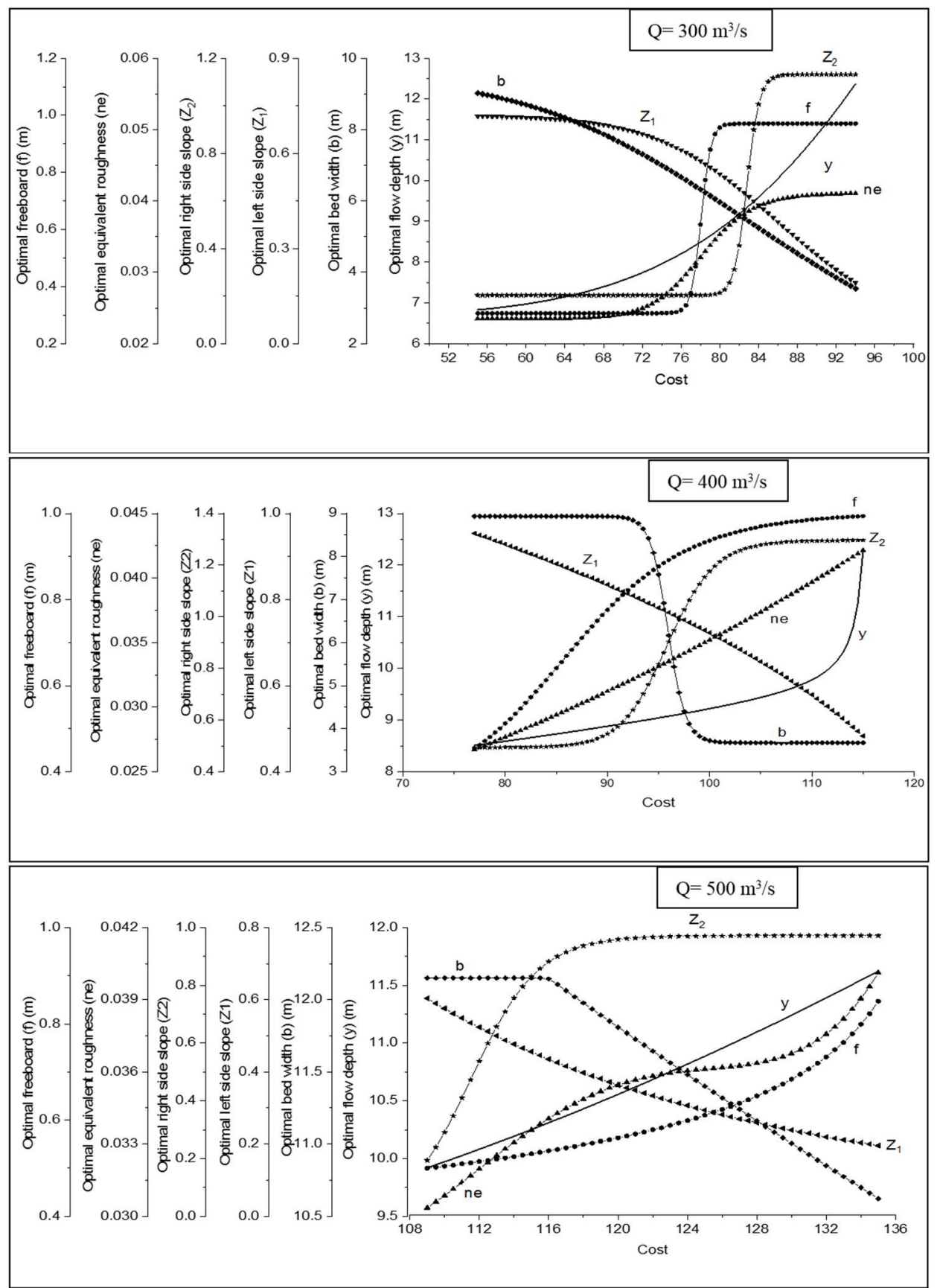




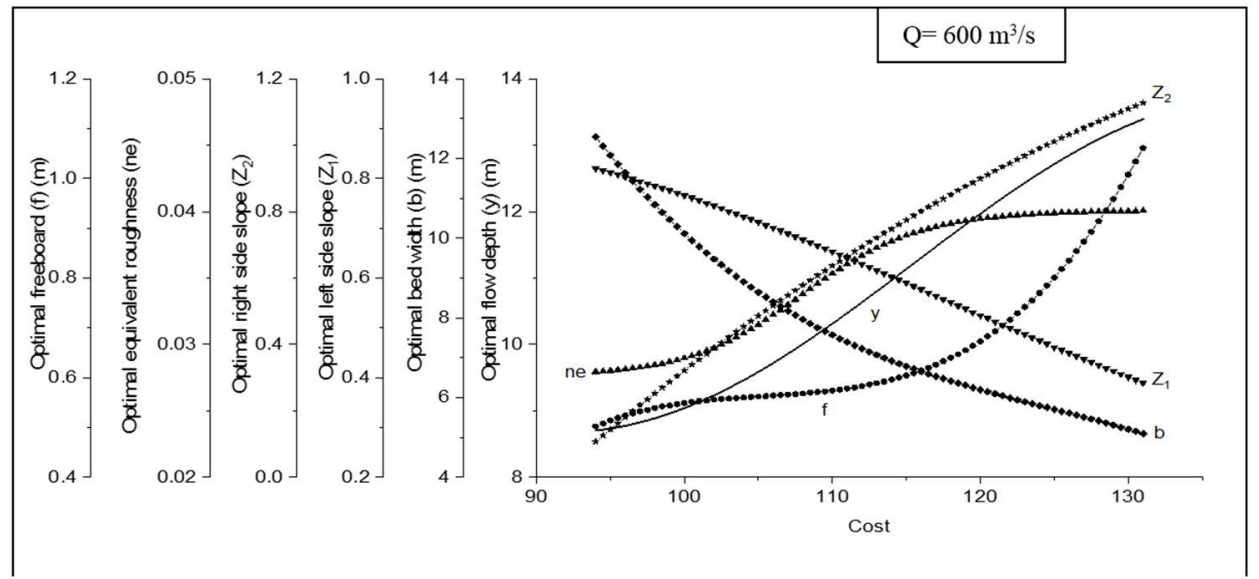

Fig. 3. Illustration of cost graphs and design variables for a specified discharge

\section{CONCLUSION}

In this study, the optimal design for trapezoidal composite channel cross-sections was prepared with different discharge values by presenting both conceptual and analytical models. The channel construction cost was considered as the objective function. Depth of flow, channel width, side slopes, side and bed roughness coefficients, and freeboard were considered as design variables. In addition, Manning's equation, Froude number, water surface width, and flow velocity were considered as constraints. The SPSA optimization algorithm was applied to optimize the trapezoidal channel cross-section with 12,000 iterations and a zero convergence condition of the penalty function. For each discharge value, the three top conceptual models were selected. Finally, the conceptual model of $\frac{y \cdot z_{2} \cdot n_{e} \cdot f}{b \cdot z_{1}} \propto$ Cost extracted at all discharge values was selected as the top conceptual model and was considered as the basis of the mathematical models for the optimal channel design. Then, the mathematical models of channel construction cost are presented based on design variables, Froude number, flow velocity, and channel depth for each specified discharge. Also, for different discharge values, a mathematical model is presented between the channel construction cost and each of the design variables.

At different discharge values, evaluation criteria were considered for selecting the best analytical models of the p-value, error sum of squares, coefficient of determination, and AIC. Construction cost increases with increasing water depth, channel left side slope, equivalent roughness coefficient, and freeboard and with decreasing channel width and channel cross-section right side slope. This process is the same in different discharge values. 


\section{Conflict of Interest}

The authors declare that they have no conflict of interest.

\section{REFERENCES}

1. Guo, CY and Hughes, WC 1984. Optimal channel cross-section with freeboard. Journal of irrigation and drainage engineering 110(3), 304313.

2. Chow, VT 1959. Open channel hydraulics. New York: McGraw-Hill.

3. Das, A 2000. Optimal channel cross-section with composite roughness. Journal of irrigation and drainage engineering 126(1), 68-72.

4. Loganathan, GV 1991. Optimal design of parabolic canals. Journal of Irrigation and Drainage Engineering 117(5), 716-735.

5. Swamee, PK 1995. Optimal irrigation canal sections. Journal of Irrigation and Drainage Engineering 121(6), 467-469.

6. Swamee, PK, Mishra, GC and Chahar BR 2000. Comprehensive Design of Minimum Cost Irrigation Canal Sections. Journal of irrigation and drainage engineering 126(5), 322-327.

7. Babaeyan-Koopaei, K, Valentine, EM and Swailes, DC 2000. Optimal design of parabolic-bottomed triangle canals. Journal of Irrigation and Drainage Engineering 126(6), 408-411.

8. Jain, A, Bhattacharjya, RK and Sanaga, S 2004. Optimal design of composite channels using genetic algorithm. Journal of Irrigation and Drainage Engineering 130(4), 286-295.

9. Chahar, BR 2005 Optimal design of a parabolic canal section. Journal of Irrigation and Drainage Engineering 131(6), 546-554.

10. Bhattacharjya, RK 2006 Optimal design of open channel section incorporating critical flow condition. Journal of irrigation and drainage engineering 132(5), 513-518.

11. Bhattacharjya, RK and Satish, MG 2007. Optimal design of a stable trapezoidal channel section using hybrid optimization techniques. Journal of Irrigation and Drainage Engineering 133(4), 323-329.

12. Reddy, MJ and Adarsh, S 2010. Chance constrained optimal design of composite channels using meta-heuristic techniques. Water Resources Management 24(10), 2221-2235.

13. Roushangar, K, Alami, MT, Nourani, V and Nouri, A 2017. A cost model with several hydraulic constraints for optimizing in practice a trapezoidal cross-section. Journal of Hydroinformatics 19(3), 456-468.

14. Gupta, SK, Mishra, U, Datta, D and Singh, VP 2018. Fish shoal optimization for identification of the most suitable revetment stone for 
design of minimum cost earthen canals carrying sediment-laden flow. ISH Journal of Hydraulic Engineering 24(2), 172-189.

15. Han, YC, Easa, SM and Gao, XP 2019. General explicit solutions of most economic sections and applications for trapezoidal and parabolic channels. Journal of Hydrodynamics 31(5), 1034-1042.

16. Farzin, S and Valikhan Anaraki, M 2020. Optimal construction of an open channel by considering different conditions and uncertainty: application of evolutionary methods. Journal of Engineering Optimization 16, 1-9.

17. Saplioglu, K, Ozturk, TSK and Acar, R 2020. Optimization of open channels using particle swarm optimization algorithm. Journal of Intelligent \& Fuzzy Systems 39, 399-405.

18. Horton, RE 1993. Separate roughness coefficients for channel bottom and sides. Engineering News Record 111(22), 652-653.

19. Swamee, PK, Mishra, GC and Chahar, BR 2002. Optimal design of transmission canal. Journal of Irrigation and Drainage Engineering 128(4), 234-243.

20. Spall, JC 1998. An overview of the simultaneous perturbation method for efficient optimization. Johns Hopkins Apl. Technical Digest 19(4), 482492.

21. Pouraminian, M. and Ghaemian, M 2015. Shape optimisation of concrete open-spandrel arch bridges. Građevinar 67(12), 1177-1185.

22. Pourbakhshian, S and Ghaemian, M 2016. Shape optimization of arch dams using sensitivity analysis. KSCE Journal of Civil Engineering 20(5), 1966-1976.

23. Seyedpor, SM, Salajegheh, J, Salajegheh, E and Gholizadeh, S 2011. Optimal design of arch dams subjected to earthquake loading by a combination of simultaneous perturbation stochastic approximation and particle swarm algorithms. Applied Soft Computing 11(1), 39-48.

Editor received the manuscript: 27.01.2021 